\title{
Fortalecimiento del proceso lector a través de las Tecnologías de la Información y la Comunicación1
}

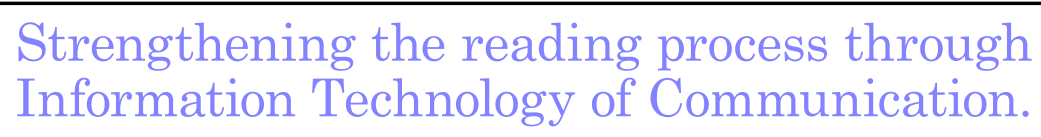

DOI: http://dx.doi.org/10.17981/cultedusoc.9.3.2018.99

Artículo de investigación. Fecha de recepción: 15/06/2018. Fecha de aceptación: 27/11/2018

\author{
Neys Esquea Valencia²; \\ Enel Pertuz Palmera; María Orozco Obredor; \\ Neys Esquea Valencia; Nubeth Orozco Racinez; \\ Patricia Guette Carrillo y Wilfrido Suarez Varela ${ }^{3}$ \\ Institución educativa departamental Liceo Zapayan , sede \#6 CEB Piedras Pintadas (Colombia) \\ neysjosesua@hotmail.com
}

Para citar este artículo:

Esquea, N., Pertuz, E., Orozco, M., Esquea, N., Orozco, N., Guette, P. y Suarez, W. (2018). Fortalecimiento del proceso lector a través de las Tecnologías de la Información y la Comunicación. Cultura. Educación y Sociedad 9(3), 835-840. DOI: http://dx.doi.org/10.17981/ cultedusoc.9.3.2018.99

\section{Resumen}

El propósito de la investigación radica en el fortalecimiento del proceso lector a través de las herramientas de las Tecnologías Informáticas de la Comunicación (TIC). La unidad de análisis estuvo constituida por lo estudiantes del grado 5 , entre las edades de 10 y 11 años. Se utilizaron como herramientas de recolección de información la encuesta y la observación. Se halló que las estrategias que más agradan a los estudiantes para leer son a través de los cuentos con un $68 \%$, luego le sigue la poesía con un $25 \%$, siendo los últimos la fábula con $4 \%$ y revista con el 3\%. A partir de estos resultados la encuesta realizada, evidencia la necesidad imperante de dinamizar el proceso de enseñanza de la lectura, a través de herramientas tecnológicas que dinamicen el ejercicio y se ajusten a las necesidades de los estudiantes en virtud de las dificultades lectoras período tras período.

\section{Abstract}

The purpose of the research lies in the strengthening of the reading process through the tools of Information Technologies of Communication (ICT). The unit of analysis was constituted by students of grade 5 , between the ages of 10 and 11 years. The survey and observation were used as information collection tools. It was found that the strategies that most please students to read are through stories with $68 \%$, followed by poetry with $25 \%$, the last being the fable with $4 \%$ and magazine with $3 \%$. Based on these results, the survey shows the prevailing need to boost the teaching process of reading, through technological tools that dynamize the exercise and adjust to the needs of students by reading difficulties period after period.

1 Este artículo ha sido derivado del Proyecto Fortalecimiento de la Cultura Ciudadana y Democrática en CT+I a través de la IEP apoyada en TIC en el Dpto. del Magdalena

2 Líder del grupo de investigación "Los novedosos".

3 Docentes de la institución educativa departamental Liceo Zapayan, sede \#6 CEB Piedras Pintadas.

- The author; licensee Universidad de la Costa - CUC.

Cultura, Educación y Sociedad vol. 9 no. 3, pp. 835-840. Diciembre, 2018

Barranquilla. ISSN 2389-7724 Online 


\section{Introducción}

La actividad de lectura se hace presente en todos los niveles educativos, tanto es la presencia que se comienza a una edad temprana como el preescolar con lecturas de imágenes. Para Solé (1998) la lectura es un proceso en el cual el lector interactúa con el texto, con el objetivo de obtener una información específica, para sintetizar los objetivos que lo llevaron al acto de la lectura. La lectura pasa a comprender el significado potencial de mensajes registrados a través del procesamiento de lo leído, ya que, al enseñar a niños y niñas a leer o a conocer los sonidos que las letras representan, $\mathrm{y}$, al mismo tiempo, invitarlo a que se vuelvan lectores, es una tarea que se vuelve difícil.

Los estudiantes de los grados 3,4 y 5 del Instituto Educativo Departamental Liceo Zapayan sede \#6 CEB Piedras Pintadas presentan problemas de lectura, así mismo, tienen problema en las diferentes áreas del conocimiento porque no comprenden los textos. En una encuesta realizada por los docentes, se pudo detectar que un $85 \%$ de niños y niñas tienen dificultades para leer, de igual manera se hizo con los padres de familia y detectamos algunas causas, tales como: falta de compromiso de los estudiantes en la práctica de lectura, el no acompañamiento de los padres para despertar en ellos el ámbito de lectura, además, que los estudiantes no tienen acceso a periódicos, revistas y/o murales.

Otros aspectos para mencionar son la falta de herramientas tecnológicas para el buen desarrollo y el hábito de lectura, también un porcentaje alto de analfabetismo en los padres de familia de la comunidad de Piedras Pintadas. La falta de comprensión lectora afecta no sólo a los educandos de primaria sino también a los de niveles superiores, causando un bajo rendimiento escolar en todas las asignaturas, por tal motivo se hace necesario abordar este problema con el fin de reducir las consecuencias de éste.
Para ello se debe tener en cuenta que el desarrollo de la competencia lectora no es tarea fácil, en ella intervienen factores de todo tipo: cognitivos, sensoriales, motrices, emotivos, sociales; que han de conjugarse necesariamente para lograrlo.

La siguiente investigación ha sido realizada con el fin de encontrar la respuesta a la inquietud que ha tenido el grupo, donde va a permitir conocer cuál es el verdadero potencial de la lectura en la vida de los estudiantes.

La razón de donde nace esta inquietud es saber hasta dónde llega la imaginación de los niños donde puedan entender lo que pasa a su alrededor a través de juegos y lecturas, qué tanto manejan la creatividad y la intelectualidad, y también cuál es su capacidad mental al jugar con lecturas de su interés que ha sido el principal objetivo que tomo el grupo para llevarnos a esta investigación y darle respuesta a lo que queremos experimentar con los niños de la primera infancia.

\section{La lectura}

Los seres humanos como seres sociales y culturales, desde antes de su nacimiento empiezan a leer por medio de sus sentidos, las palabras de sus padres, las canciones, los distintos sonidos que los rodean; luego al nacer leen los gestos de su madre, sus familiares y con el crecimiento evoluciona también su capacidad lectora; son capaces de leer el espacio que los rodea, el contexto, las situaciones y las imágenes; lo cual implica que leen la realidad mediados por la formación que van teniendo, la integración familiar, sus historias vividas y la cultura, y al ingresar a la escuela es cuando inicia el proceso de aprendizaje de la lectura y descifran la palabra como tal.

Leer es un acto complejo que implica mucho más que la decodificación. Leer es un proceso donde el sujeto construye significados a partir de lo que sabe, más la información visual que encuentra en los textos. Leer 
es un acto de construcción activa, donde se lleva a cabo un proceso de interacción entre el lector y el texto.

En el complejo acto de leer, hay un aspecto de vital importancia que no se puede dejar de lado y es el contexto familiar del niño, sus costumbres, cultura, educación de los padres inciden directamente en el proceso de la lectura.

Sobre el tema, Ferreiro y Teberosky (2005) manifiesta, que el ser humano debe ser lector y crítico de textos que leen, de manera que le encuentre el significado de la palabra escrita, es decir, la lectura es un acto donde el ser humano acepta la asignación de encontrarle sentido y coherencia a lo que el autor refleja en su escrito, por lo tanto, el lector debe reaccionar al momento de leer, buscando sentido de lo que se quiere expresar. Siempre tomamos en cuenta que la lectura es una actividad que nos permite identificar, decodificar y analizar lo que otra persona quiere decir, pero debemos tener en cuenta que no solo es un acto donde el ser humano decodifica signos gráficos, sino que va más allá, aceptando la responsabilidad de buscar un sentido del texto y transformar los conocimientos previos por los conocimientos recientemente aprendidos.

Por su parte, Teberosky (2005) se refiere a la lectura como un medio a través del cual el ser humano procesa de manera sistematizada la información recibida a través de códigos gráficos, integrando otros procesos como la comprensión y el análisis de la información; del mismo modo señala, que el hombre ha inventado máquinas para aumentar o disminuir la distancia, como la rueda, la palanca o el propio automóvil, pero será la lectura la que lo llevará a comprender la ciencia y el sentido propios de la vida.

Hablar de lectura y escritura desde una perspectiva constructivista, implica tener una mirada de niño y niña, desde el mismo sentido. Se conciben como sujetos cognoscentes, activos que construyen conocimiento mediante:
- Sus propias acciones sobre los objetos del mundo.

- La confrontación de los resultados de sus acciones con sus propios conceptos.

- La confrontación de los resultados de sus acciones con conceptos de otros.

Desde esta mirada, Ferreiro y Teberosky (1979), tomando como base los planteamientos de Piaget, definen al niño y la niña, como ese sujeto activo que compara, excluye, ordena, categoriza, reformula, comprueba, formula hipótesis, reorganiza, etc., en acción interiorizada (pensamiento) o en acción efectiva (según su nivel de desarrollo).

Ahora bien, en este contexto, lo que se conoce comúnmente como "errores" en realidad son requisitos para la construcción de conocimiento y que se podría llamar mejor, errores constructivos. Esta afirmación resulta contradictoria, cuando aún y en su gran mayoría se encuentran escuelas donde tratan de eliminar a toda costa los llamados "errores", sin tener en cuenta que hacen parte esencial para la construcción del conocimiento.

Leer es un proceso de construcción de significados a partir de la interacción entre el texto, el contexto y el lector obteniendo como resultado la comprensión; este un proceso interactivo en el cual el lector construye una representación organizada y coherente del contenido del texto relacionándolo con los conocimientos previos.

Cada lector hace su propia comprensión de un texto de acuerdo con su realidad interior, con su experiencia previa, con su nivel de desarrollo cognitivo y con su estado emocional, etc.

\section{Las TIC en el proceso lector}

En la actualidad existen numerosos cambios en los mercados, competencias, organizaciones, tecnologías, sociedades y culturas, entre otros, razón por la cual se considera poco pertinente seguir maniobrando bajo el mismo enfoque tradicional. Para lograr ser competitivo dentro de este entorno tan car- 
gado de dinamismo y turbulencia, es indispensable buscar la competitividad, las ventajas competitivas y por ende un desarrollo económico a largo plazo, así como también desarrollar capacidad para producir, circular y utilizar correctamente la información, la comunicación y el conocimiento, por cuanto ellos constituyen la materia prima de esta nueva sociedad.

Desde tal perspectiva Mujica (2000), considera que el avance tecnológico de la informática, la computación, y las telecomunicaciones, incorporaron en las organizaciones un enfoque diferente al habitual para acceder al conocimiento, flexibilidad, interactividad, economía, rapidez, independencia, comunicación y desarrollo.

Es un novedoso prototipo impulsado por la plataforma tecnológica, como lo refieren Negroponte (1996) y Gates (1997), el desafío es desarrollar una integración de las redes y otros recursos tales como los teléfonos, el internet, la radio, la televisión, el cable, y el internet, como fuentes de información y de comunicación para estimular la indagación y la construcción de sus aprendizajes de forma diversa, discutiendo y argumentando en relación con el aporte de sus contenidos en favor de un futuro sustentable.

En este documento se hace una distinción de los dos aspectos que componen las TIC, en primer lugar, están las Tecnologías de la Comunicación (TC) en éstas entrarían: la telefonía convencional, la radio y la televisión. En segundo lugar, estarían las Tecnologías de la Información (TI), en éstas estarían por ejemplo la informática y la telemática. Se señala la importancia de estas tecnologías para la sociedad actual, sobre todo en lo que tiene que ver con los costos y la velocidad de transmisión de la información.

De todo lo anterior queda claro que las TIC son herramientas de gran utilidad que posibilidad el acceso, manejo, procesamiento y difusión de la información en una sociedad que cada día está más interconectada y que exige de sus miembros nuevas actitudes y aptitudes frente al conocimiento.
El razonamiento expuesto hasta ahora destaca la importancia de la lectura para mejorar la enseñanza y el aprendizaje de los alumnos. En consonancia con él, sería necesario que se estableciera un tiempo de lectura semanal en todas las áreas y materias del currículo, lo que supondría que todos los alumnos dedicaran media hora o una hora diaria a la lectura. No se trata sólo, que los alumnos lean cuentos o literatura durante el tiempo escolar, lo que ya sería un logro importante.

La propuesta que formulo va más allá y plantea que la mayoría de las materias curriculares disponga de un tiempo semanal (media hora o una hora), que se dedique a la lectura de textos relacionados con sus objetivos y contenidos específicos: textos geográficos, históricos, medioambientales, de animales, artísticos, científicos, deportivos, etc. Deberían ser lecturas planificadas cuando se diseñase la asignatura correspondiente y relacionada con los objetivos de aprendizaje que en ella se establezcan.

\section{Metodología}

En este estudio, se desarrolló un diseño de investigación de carácter descriptivo, se realizaron y registraron observaciones de la realidad mediante técnicas de recolección de datos, orientadas por los objetivos de este trabajo con las técnicas e instrumentos tales como la encuesta y la observación (Tamayo, 1999; Bizquera, 1990).

La encuesta aplicada permitió recoger el flujo informativo en la población, en cuanto a sus características, conductas o actitudes significativas para esta investigación específica (Cerda, 1991).

Se utilizó la observación participante, que se refiere a la introducción de la investigación en el escenario de estudio, funcionando éste como instrumento de recogida de datos. En palabras de Taylor y Bogdan (1986) "involucra la interacción social entre el investigador y los informantes en el medio de los últimos, y durante la cual se recogen los datos de modo natural y no intrusivo". 


\section{Resultados}

Tras la encuesta realizada, se nota y sostiene la necesidad imperante de dinamizar el currículo cuyo fin último seria atender a las necesidades de los estudiantes de la sede Piedras Pintadas, en virtud las dificultades lectoras periodo tras periodo.

En los gráfico se puede observar que a la mayoría le gusta leer, pero según la observación que se realizó aún tienen problemas y dificultades.

Se puede observar que los estudiantes le gustan más los cuentos con un $68 \%$, luego le sigue la poesía con un $25 \%$, siendo los últimos la fábula con $4 \%$ y revista con el $3 \%$. Además de eso podemos notar que los estudiantes no conocen mucho sobre los tipos de texto.

Los estudiantes prefieren leer en el colegio que en cualquier lugar en del pueblo teniendo el $68 \%$, luego la casa con el $25 \%$ y algunos cambian el ambiente y les gusta leer a la orilla de la ciénaga.

Los niños prefieren compartir sus lecturas con sus pares, ya sea en el colegio o por su casa, pero tienen un porcentaje bajo, al compartirlo con sus maestros.

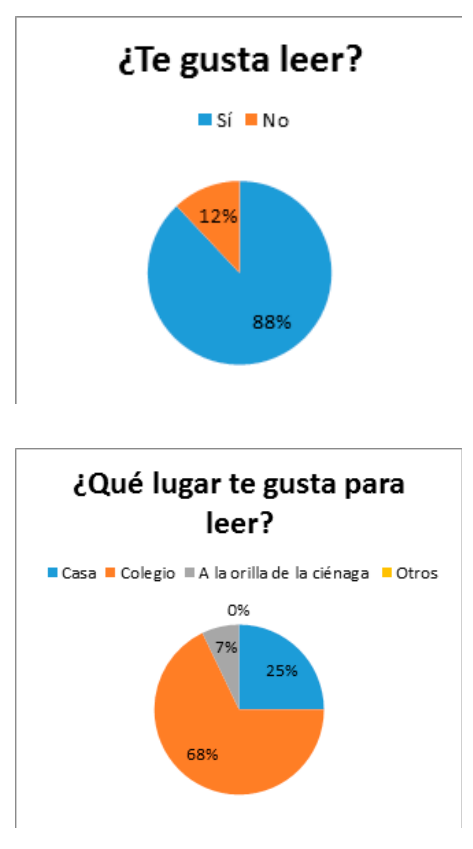

En el desarrollo humano integral, misión básica de la educación, la lectura es el medio primordial que ayuda a ampliar su conocimiento del mundo, a razonar argumentativamente, a desarrollar competencias para comunicarse y relacionarse de manera responsable y comprensiva con los pares, a facilitar la creatividad y a disfrutar las ideas que representamos con la magia de las palabras. Es así como profesores y alumnos viven la experiencia de compartir el aprendizaje con la convicción de que está desarrollándose y aprendiendo con la felicidad, desde la vida misma y la que está reflejada en los libros, en los textos y en los medios de comunicación.

\section{Discusión}

El proceso de lectura, es uno de los caminos al conocimiento más directos y amplios que puedan existir, ya que además, de poner a prueba conocimientos previos de cada uno de los lectores, llama a la investigación, incita la curiosidad y profundización, rompe con algunos esquemas y certezas que muchas veces se tienen y obstaculizan el proceso de conocimiento.

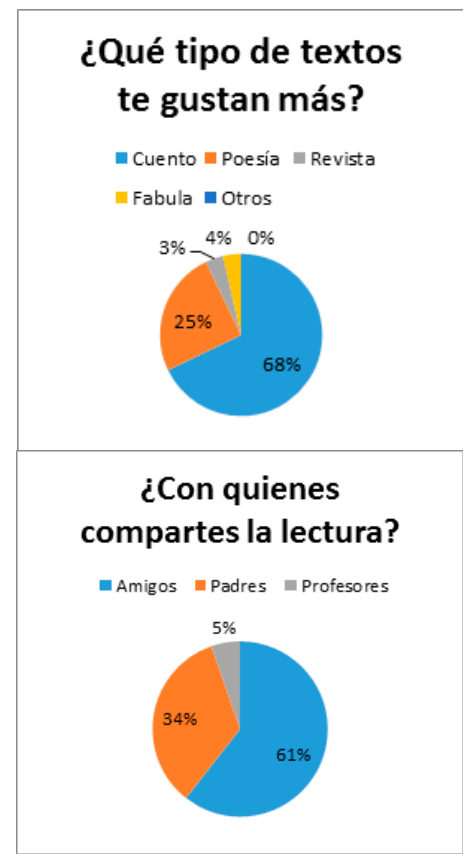


Por lo anterior, dando respuesta al objetivo general planteado se busca seguir implementando estrategias novedosas a través de las Tecnologías Informáticas de la Comunicación (TIC) y la Investigación como Estrategia pedagógica para ampliar los caminos hacia el proceso lector de los estudiantes de los grados 3,4 y 5 del IED Liceo Zapayan sede \#6 CEB Piedras Pintadas, en los cuales se busca fortalecer el nivel de lectura y la compresión de textos.

\section{Referencias}

Bizquera, R. (1990). Definición de las técnicas. [Tesis de Pregrado]. Recuperado de http://www.unerg.edu.ve/index. php?option $=$ com_docman\& task $=d_{\text {doc }}$ view\&gid=275.p. 28 .

Cerda, H. (1991). Los elementos de la Investigación. Bogotá, D.C: El Búho.

Ferreiro, E. y Teberosky, A. (2005). Los sistemas de escritura en el desarrollo del niño. México, D.F: Editores Siglo XXI.

Ferreiro, E., y Teberosky, A. (1979). Os sistemas de escritura no desenvolvimento do niño. Madrid: Século XXI.

Gates, B. (2000). Los negocios en la era Digital. España: Plaza \& James Editores, S.A.

Graells, P. (2000). Seguridad en redes sociales. Recuperado de http://tecnologymao92.weebly.com/concepto-de-lastics.html
Manjarres, M. (2007). La investigación como estrategia pedagógica del programa ondas de Colciencias. Recuperado de http://www.cientec.or.cr/pop/2007/COMariaManjarres.pdf

Mujica, M. (2000). Nuevas Estrategias para Gerenciar. Una Visión Epistemológica. Revista UNESR. Gerencia - Sociedad, 1(1), 61-76.

Negroponte, N. (1996). Ser Digital. España: Ediciones B. S.A.

Núñez, E., Vergara, R. y Bocanegra, J. (2014). Sistema experto basado en lógica difusa tipo 1 para determinar el grado de riesgo de preeclampsia. INGE CUC, 10(1), 43-50. Recuperado de https://revistascientificas.cuc.edu.co/ingecuc/article/ view/341

Patiño, A. (2015). Tendencias tecnológicas que influyen en el aumento de la productividad empresarial. INGE CUC, 11(2), 84-96. https://doi.org/10.17981/ingecuc.11.2.2015.09

Smith, F. (1995). Comprensión de la lectura. México, D.F: Editorial Trillas.

Solé, I. (1998). Estratégias de Leitura. Trad: Cláudia Schilling (6 ${ }^{\mathrm{a}}$ ed). Porto Alegre: Artmed

Tamayo, M. (1999). Metodología formal de la investigación científica. Bogotá, D.C.: LIMUSA.

Taylor, S. y Bogdan, R. (1986). Introducción a los métodos cualitativos de investigación. Barcelona: Paidós.

Teberosky, A. (2005). Los sistemas de escritura en el desarrollo del niño (22 Edición). México, D.F.: Siglo XXI. 